\section{REVALORIZAÇÃO DO PATRIMÔNIO HISTÓRICO EM ÁREAS INDUSTRIAIS: O CASO DO 4 DISTRITO EM PORTO ALEGRE - RS}

\author{
Revalorization of historical heritage in industrial areas: the case of the $4^{\text {th }}$ district in Porto \\ Alegre - RS
}

\section{Pedro Toscan Pittelkow Contassot Tânia Marques Strohaecker**}

\begin{abstract}
*Mestre em Geografia pela UFRGS - pedrotoscan@gmail.com **Professora Doutora do Programa de Pós-Graduação em Geografia da UFRGS - tania.strohaecker@ufrgs.br
\end{abstract}

Recebido em 25/06/2019. Aceito para publicação em 30/07/2019.

Versão online publicada em 10/09/2019 (http://seer.ufrgs.br/paraonde)

\begin{abstract}
Resumo:
Esta pesquisa apresenta o patrimônio cultural urbano, tomado como elemento de revalorização do espaço, considerando o caso do $4^{\circ}$ Distrito de Porto Alegre - RS, antiga área industrial, atualmente desprovida de dinamismo econômico e demográfico. Identifica-se a preservação da forma urbana, que evocaelementos estéticos do patrimônio cultural, ao passo em que a substituição das funções objetiva recuperar o dinamismo econômico. Nesse contexto, surgem os agentes voltados à economia criativa, que se instalam na área, até então, considerada pouco atrativa. Após a chegada dessas classes pioneiras, o poder público e as incorporadoras imobiliárias buscam requalificar a região, valendo-se do patrimônio como estratégia de valorização econômica. O surgimento de regramentos específicos, que se sobrepujam ao Plano Diretor de Porto Alegre, suscita o questionamento da efetividade da participação cidadã nos espaços decisórios do planejamento urbano.
\end{abstract}

Palavras-chave: Patrimônio cultural urbano; Revalorização imobiliária; 4ํㅡㄴ Distrito de Porto Alegre.

\begin{abstract}
:
This research presents the urban cultural patrimony, taken as an element of spatial revaluation, considering the matter of the 4th District in Porto Alegre - RS, an old industrial area, currently devoid of economic and demographic dynamism. It identifies the preservation of the urban form, evoking aesthetical elements of the cultural patrimony, whereas the substitution of the functions aims the recovery of its economic dynamism. In this context, agents focused on creative economy emerge and settle in the area, until then, considered unattractive. After the arrival of these pioneer classes, public sector and real estate developers seek to requalify the region, using patrimony as a strategy of economical revaluation. The emergence of specific regulations, that surpass the city's Masterplan, raise the questioning of effectiveness of citizen participation in decision-making spaces of urban planning.
\end{abstract}

Key-words: Urban cultural patrimony; Real estate revaluation; 4th District of Porto Alegre.

\section{Introdução}

O 4ํㅡㄹ Distrito de Porto Alegre é uma área de antiga atividade fabril, cuja ocupação data do final do Século XIX. Considerada uma das áreas mais dinâmicas da cidade na primeira metade do Século XX, sofreu perda de densidade demográfica e de dinamismo econômico após a década de $1970^{1}$, período em que diversas outras cidades brasileiras também passaram por processos

${ }^{1}$ CONTASSOT, P. T. P. Transformações no padrão de habitação do $4^{\circ}$ Distrito de Porto Alegre. Monografia (Bacharelado em Geografia) - Instituto de Geociências, Universidade Federal do Rio Grande do Sul, Porto Alegre. 2014. 101 p. Disponível em: https://www.lume.ufrgs.br/bitstream/handle/10183/114634/000955442.pdf?sequence=1> 
de desconcentração industrial em direção às suas respectivas regiões metropolitanas.

No momento atual, os elementos constitutivos desse espaço são tomados como amenidades, entre os quais é possível elencar o terreno plano, as vias largas, o traçado xadrez, a acessibilidade facilitada através de conexões com as rodovias BR-116, BR-290 e BR-448, com o Lago Guaíba e com o Centro Histórico da cidade. Dentro desse panorama, o patrimônio surge como um componente chave na preservação de uma ambiência urbana, a partir dos principais marcos imagéticos que mantém viva a história e a arquitetura, remetendo à prosperidade e à pujança econômica da primeira metade do século XX. Em função da sua localização estratégica na Região Metropolitana de Porto Alegre (RMPA), como entrada da cidade, e da proximidade dos terminais aeroviário e rodoviário, a área se configurou como alvo de recentes iniciativas de requalificação urbana. A localização do 4ํㅡㄹ Distrito no município de Porto Alegre se apresenta na Figura 1.
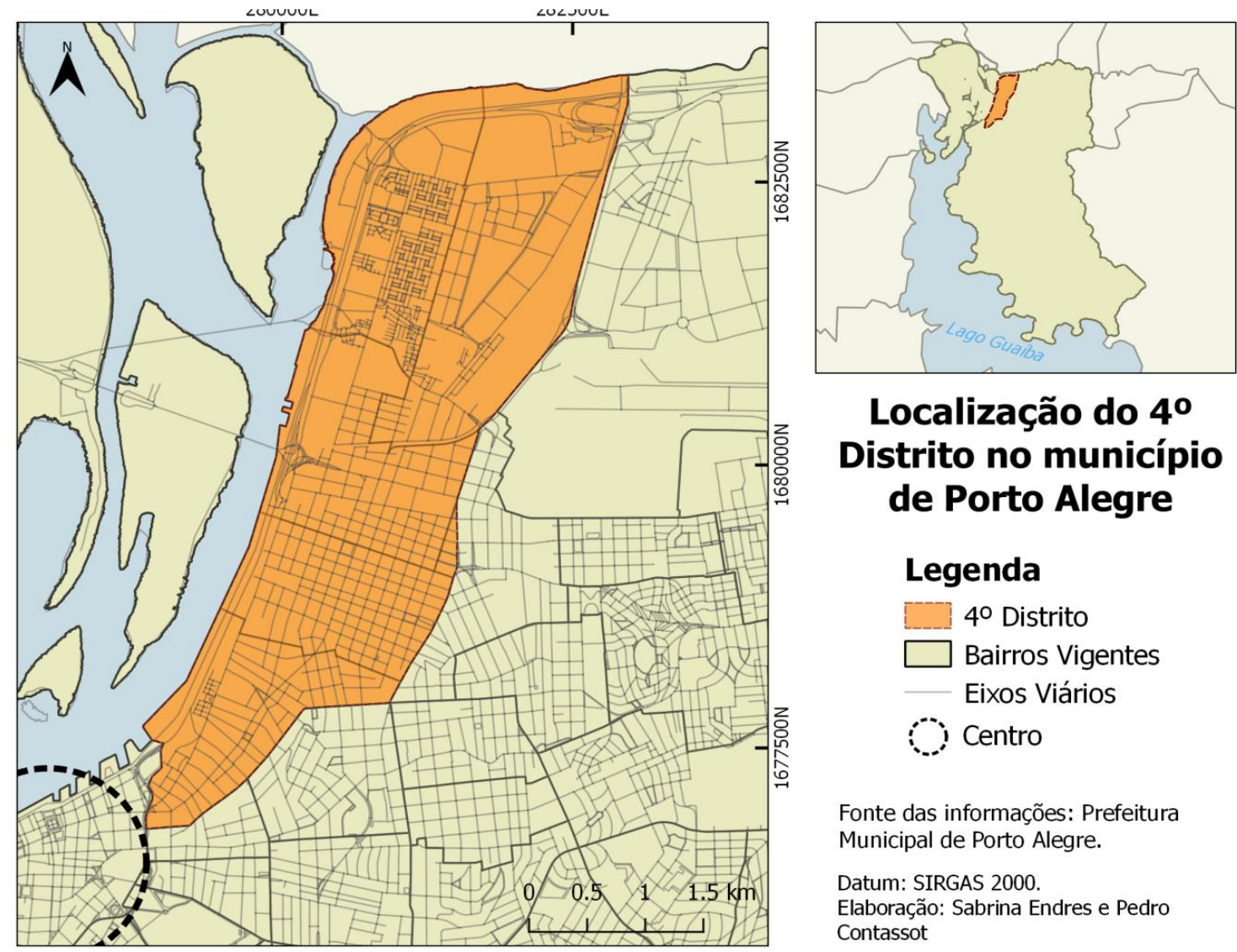

\section{Legenda}

40 Distrito
$\square$ Bairros Vigentes
Eixos Viários
Centro

Fonte das informações: Prefeitura Municipal de Porto Alegre.

Datum: SIRGAS 2000.

Elaboração: Sabrina Endres e Pedro Contassot

Figura 1 - Localização do 4º Distrito no município de Porto Alegre Fonte: Sabrina Endres e Pedro Contassot.

Objetiva-se harmonizar a herança do passado industrial com futuros polos de tecnologia, de educação de nível superior e de saúde, recuperando edificações abandonadas e mesclando-as com novos equipamentos de uso coletivo, promovendo um aumento de densidade habitacional que supera o previsto pelo Plano Diretor de Desenvolvimento Urbano Ambiental, formulado em 1999 e revisado em 2010. Desenvolve-se, a partir disso, o Masterplan do 4ํㅡㄴ Distrito ${ }^{2}$, regramento específico para a área, que promove um regime urbanístico diferenciado. Reverberações desse plano estratégico na esfera da preservação suscitam a questão: qual será o futuro do passado de Porto Alegre?

${ }^{2}$ Certificação, no endereço eletrônico da Prefeitura Municipal de Porto Alegre, do Masterplan promovido pelo Núcleo de Tecnologia Urbana da Universidade Federal do Rio Grande do Sul (NTU - UFRGS): <http://www2.portoalegre.rs.gov.br/spm/default.php?p_noticia=190964\&UFRGS+APRESENTA+ESTUDO+DE+REVIT ALIZACAO+DO+4O+DISTRITO> 


\section{O patrimônio cultural urbano: apontamentos conceituais}

A preservação do patrimônio é um tema premente no espectro da requalificação urbana, que suscita elementos tradicionais, referentes ao passado, e elementos tecnológicos e criativos, preconizando o desenvolvimento com vistas ao futuro. Contudo, na cidade contemporânea, a revalorização econômica oculta-se no discurso da modernização, pautada nos interesses privados, que se sobrepujam à esfera estatal e municipal na elaboração e implementação de políticas públicas. Assim, o governo local submete-se a um papel de mediador nas estratégias de consolidação de um modelo de êxito globalmente difundido, ancorado na criatividade como um de seus conceitos balizadores.

Porto Alegre é um dos municípios pioneiros no tratamento do patrimônio no Brasil. Cabe, portanto, discriminar o entendimento de patrimônio que se faz, dentre suas diversas acepções. Meira (2004), na obra "O passado no futuro da cidade", baliza o conceito de patrimônio que será utilizado neste estudo. Trata-se de um "patrimônio cultural urbano" (MEIRA, 2004, p. 27), de onde é possível fragmentar os três termos para, depois, tomar o conceito em sua totalidade. $O$ primeiro termo, "patrimônio", origina-se associado a "paterno" e a "pátria", remetendo à herança, legado, posse; apropriado ou por um indivíduo ou por uma coletividade (MEIRA, 2004, p. 23). O segundo termo, "cultural", especifica que a compreensão se focaliza, aqui, no campo da coletividade, porque as referências que o patrimônio suscita são socialmente construídas, relacionando-se com a dimensão simbólica e as narrativas que justificam a permanência desse legado. Trata-se, sobretudo, de uma questão de pertença. O terceiro termo, "urbano", funciona não somente como um elemento de circunscrição do patrimônio como algo próprio da urbe, mas, além disso, atenta para sua dinâmica no tempo. A cidade muda, e com ela modificam-se as leituras que essa coletividade faz do seu patrimônio, ou seja, o que deve ser preservado e o que deve ser esquecido. É plurissignificativo e em constante movimento.

O patrimônio cultural urbano é, em síntese, um fragmento preservado da história da cidade, que representa um modo de vida do passado e dá raízes na construção de um futuro comum, dando ideia de continuidade e progresso; age como um aglutinador, um legitimador simbólico de origem. Insere-se no campo das representações: o que emerge é da ordem dos olhos do espectador, que o preenche de significado. A intencionalidade depende do ente que expressa o desejo de preservar, que pode representar um interesse ora econômico, ora político, legitimada por uma visão técnica, dos planejadores ligados ao poder público, ou popular, encaminhada pela sociedade civil. A complexidade se dá no cruzamento dessas forças, de forma que seu isolamento resultaria em uma simplificação. O campo simbólico está imbuído de representações que afetam o campo da política e da economia, logo, o simbólico é estratégico para definir os rumos das políticas de preservação ou, por outro lado, seu abandono.

A visão romantizada, que consagra as virtudes do passado, não esgota as possibilidades de tratamento do patrimônio. Antes, mascara o conflito que o espaço urbano engendra para confiná-lo em uma dimensão unívoca, pasteurizada. A turistificação se beneficia dessa narrativa, pois simplifica o passado em um relato linear, quase mítico. Por outro lado, a "dimensão revolucionária do patrimônio" (MEIRA, 2004, p. 15) implica em valorizar as diversas vozes que permeiam o espaço urbano para a sua consolidação, alçando-o a uma posição crítica, que promova o desenvolvimento, distante da dimensão da atração e da contemplação. Para além de monumentos institucionais/oficiais, que falham em capturar as narrativas do cotidiano, a validade do patrimônio é garantida quando este reflete as experiências cotidianas dos cidadãos, ou seja, quando estes se percebem partícipes do processo de significação.

Para que se trate do patrimônio cultural urbano do $4^{\circ}$ Distrito, é necessário destacar a dialética da relação entre o material e o imaterial, que faz com que atuem em simbiose. No tratamento da área como um lugar, torna-se difusa a distinção entre o público e o privado, principalmente no aspecto imaterial. Aproxima-se, aqui, do conceito de lugar proposto por Castello, que classifica "lugar" como um espaço qualificado, isto é, um espaço de representação, que engendra imagens e referências, e que diz respeito às formas urbanas e à maneira que as

Para0nde!?, Porto Alegre, v.12, n.1, p.101-108, 2019. http://seer.ufrgs.br/paraonde 
pessoas interagem com essas formas. Isso pressupõe a existência de espaços onde as pessoas possam se relacionar com a cidade, interagindo tanto entre si quanto com o ambiente que as cerca (CASTELLO, 2004).

A formulação de lugar, na era da valorização do patrimônio histórico, nas palavras de Lipovetsky e Serroy (2015), "está imbuída dos princípios da hipermodernidade mercantil, estética e midiática. Com essas políticas de reconversão, o passado conservado muitas vezes aparece como uma concha vazia [...] esvaziada do valor primordial das construções" (LIPOVETSKY e SERROY, 2015, p. 323). Nesse contexto, está implicada a elaboração de uma infraestrutura voltada ao turismo, onde se esfacelam as relações de vizinhança e de comunidade.

Duas categorias auxiliam na compreensão da dimensão material/imaterial: a forma e o fenômeno urbano entendido enquanto totalidade. A forma urbana é trazida por Henri Lefebvre como:

A simultaneidade (dos acontecimentos, das percepções, dos elementos de um conjunto no "real"). [...] O encontro e a reunião daquilo que existe nos arredores, na "vizinhança" (bens e produtos, atos e atividades, riquezas) e, por conseguinte, a sociedade urbana como lugar socialmente privilegiado, como sentido das atividades (produtivas e consumidoras), como encontro da obra e do produto (LEFEBVRE, 2001, p. 90).

Nesta distinção entre produto e obra, Lefebvre define o primeiro como a produção daquilo que é do domínio científico, técnico e que sobrepuja a natureza material - e ao sentido de obra, deve-se acrescentar o sentido de apropriação (do tempo, do espaço, do corpo). A obra pertence à filosofia e às artes (LEFEBVRE, 2001) - sentidos em permanente entrelaçamento quando tratamos da refuncionalização urbana ancorada na produção cultural.

Já o fenômeno urbano, onde se insere a forma urbana, pode ser compreendido como a experiência da vida na cidade, que é complexa e abstrata, indo além da esfera do "real" e do possível. Na dimensão do fenômeno urbano é preciso levar em conta as relações invisíveis que operam nele, de produção de troca, de signos e símbolos. A desconsideração desses aspectos faz com que "evitem-se questões cruciais (por exemplo, as do centro e da centralidade, implicando o risco de ratificar seja a degradação dos centros, seja sua consolidação "elitista" e autoritária)" (LEFEBVRE, 1999, p. 50).

Um paralelo pode ser traçado entre as noções de forma e fenômeno, vistas em Lefebvre, e os sistemas de objetos e sistemas de ações desenvolvidos por Milton Santos (2006). Se a forma é o encontro da obra e do produto, ambos os objetos produzidos (científica ou culturalmente), e o fenômeno é a experiência urbana abstrata e invisível, mas percebida por meio de signos, parece possível aproximá-los do par "sistemas de objetos" (forma urbana) e "sistemas de ações" (fenômeno urbano). Os sistemas de objetos se inserem em uma totalidade, que é o espaço geográfico. Dentro desse espaço, todos os objetos são externos ao indivíduo e tornam-se "instrumento material de sua vida" (SANTOS, 2006, p. 72). Os sistemas de ações afetam a organização do espaço através desses objetos, que incidem sobre ele. Analisadas enquanto sistema, as ações são definidas como um processo no qual o indivíduo, ao exercer trabalho, modifica seu meio e a si mesmo. O agir pode ser de três tipos: técnico, formal e simbólico. $\mathrm{O}$ agir técnico é limitado por uma técnica situada no tempo e no espaço. O agir formal é determinado pelo conjunto de regramentos jurídicos. O agir simbólico compreende dinâmicas afetivas e emotivas, ligadas ao campo da representação e da significação.

No caso do $4^{\circ}$ Distrito, a forma é distinta em sua apresentação, mas o uso é mais flexível: possui diferentes possibilidades de apropriação. Por esse motivo, pretende-se preservar os aspectos concernentes à forma, que evoca elementos estéticos do passado, e substituir suas funções, dotando a área de nova visibilidade, integrando-a a um circuito de circulação de serviços, mercadorias e pessoas. Há, portanto, uma ressignificação da atividade fabril: o que foi, no passado, valor de uso a partir da função, é, no presente, valor de troca a partir da forma. 


\section{Os agentes da economia criativa e a mercantilização do espaço}

Entre os agentes que modificaram a concepção do 4ํㅡㄹ Distrito como uma área degradada e esvaziada estão as classes voltadas à economia criativa, à tecnologia e à cultura, que ali se instalam no momento atual. Elas representam frentes pioneiras, que ocupam as áreas degradadas em busca de oportunidades, valendo-se da expressiva centralidade e dos valores de solo inferiores aos dos bairros de classe média alta. As estruturas industriais amplas permitem a criação de espaços maleáveis de moradia e trabalho, que atendem as necessidades de um grupo flexível, inovador e criativo. Esses agentes buscam se fortalecer mutuamente e criar redes de proximidade geográfica, a fim de combater a empregabilidade temporária e as jornadas de trabalho não convencionais.

Há uma união entre as virtudes da arte com as competências do mercado de trabalho: inovação, fornecimento de serviço personalizado e exclusivo. E, portanto, o trabalhador criativo tende a assemelhar-se ao artista: "inventivo, flexível, motivado, com salários incertos, concorrente de seus pares, com uma trajetória profissional instável" (VIVANT, 2012, p. 49) onde imperam as contratações por edital e/ou projeto, resultando em situações de empregabilidade temporária e de jornadas de trabalho pouco convencionais. Justamente por esse motivo, as áreas centrais foram escolhidas como sede das incursões desses novos grupos: a flexibilização contratual exige que os trabalhadores se encontrem localizados próximos às possibilidades de trabalho no setor de serviços, bem como une esses indivíduos de perfis tão diversos que partilham contextos profissionais e comungam de interesses complementares na elaboração ou execução de um novo projeto. A dificuldade de acessar crédito imobiliário, de acordo com Vivant (2012), caracteriza a retomada do centro como uma escolha contrafeita, uma vez que a locação de imóveis em antigas áreas industriais é menos onerosa e menos burocrática do que nos bairros mais valorizados.

Os agentes da economia criativa iniciam uma mudança na forma de conceber esses espaços, ressignificando os elementos que remetiam à degradação e à insalubridade em elementos atraentes e vendáveis, conferindo-os uma nova legitimidade. Inicia-se um processo de revalorização, que é tanto econômica quanto semiótica. O mundo da fábrica, abandonado pelas classes médias, é agora local de resgate da memória e do patrimônio histórico. Para que se construa o discurso da requalificação aliado à preservação do patrimônio histórico, é necessário que a área possua elementos culturais que funcionem como legitimadores das parcerias entre 0 estado e o empresariado interessado em investir na região. Ou seja: deve haver um conjunto urbanístico que remeta esteticamente a um passado adormecido de prosperidade e civilidade. Não se trata, portanto, de um resgate das memórias que evidenciem as condições precárias de trabalho às quais os operários industriais estavam submetidos, mas sim de um resgate da prosperidade da região em si mesma, ou, ainda, das memórias dos proprietários de estabelecimentos industriais da primeira metade do século XX. Essa é a prosperidade exaltada nos discursos de retomada do crescimento, uma releitura glamourizada do período industrial posta à venda para as classes médias do setor de serviços no século XXI.

É através dessa atração de novos segmentos profissionais da economia criativa que a cultura se transformou no ingrediente chave para revolucionar a maneira de pensar o "desenvolvimento urbano" na sociedade contemporânea e promover a valorização do espaço. Nessa dinâmica, o empresariado se apropria do modo de vida das classes criativas para encontrar novas formas de promover o retorno de determinados segmentos populacionais às áreas degradadas e ociosas para o capital imobiliário. O terreno da Fiateci - Companhia Fiação e Tecidos Porto Alegrense, localizado no $4^{\circ}$ Distrito, comprado pela Incorporadora Rossi, teve sua fachada original preservada e abriga, hoje, em seu interior, torres de uso comercial e residencial. Entre as propagandas que circundam os muros do terreno, é possível perceber como o patrimônio é evocado como elemento de valorização imobiliária, conforme mostra a Figura 2. 


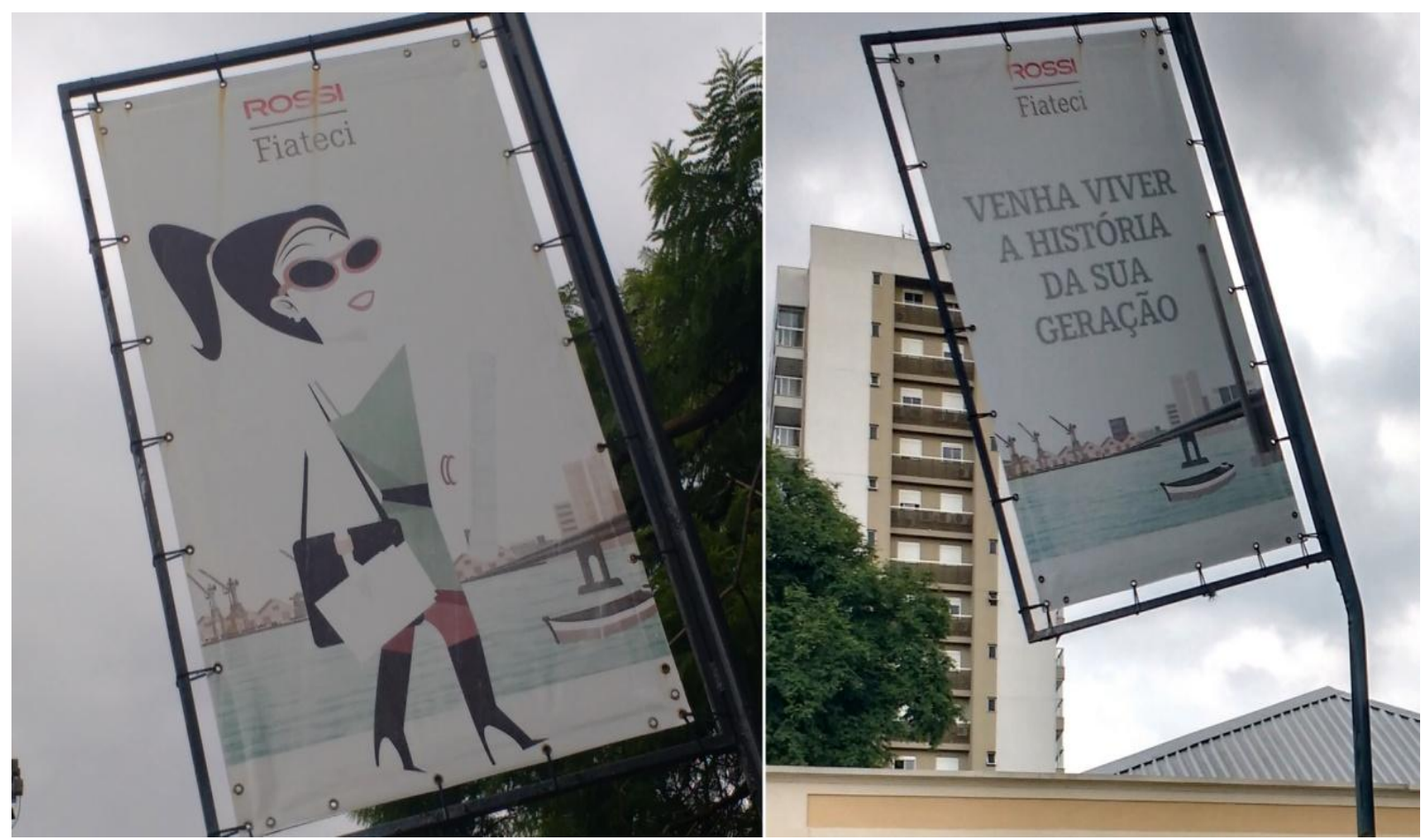

Figura 2 - Propaganda do empreendimento Rossi Fiateci, bairro São Geraldo Fonte: Pedro Contassot, 2017.

A mercantilização do patrimônio é uma das questões mais latentes na era da globalização, onde antigas áreas industriais emergem como casos de sucesso na contemporaneidade. Entre elas, podemos citar o 22@, distrito de inovação em Barcelona, os bairros SoHo e TriBeCa ${ }^{3}$, em Nova lorque, e as Docklands, em Londres, que se converteram em espaços de atividade criativa, tecnológica e de efervescência cultural. Parece haver uma receita padronizada na revalorização de espaços que apresentam patrimônio cultural urbano:

Em geral, essas intervenções seguem um modelo baseado na conhecida experiência de Barcelona, cujas principais características são: melhoria da infraestrutura urbana combinada com a revalorização do patrimônio edificado, com forte ênfase na transformação dos espaços urbanos (geralmente sítios históricos) em espaços de lazer e entretenimento para as camadas médias e altas da sociedade, com vista à adequação desses espaços às demandas de consumo cultural. Transformada em mercadoria, essas cidades "revitalizadas" adentram o circuito do chamado city marketing e promovem um aguçado processo de exclusão sócio-espacial que tem criado nichos urbanos com elevado grau de disputa simbólica pelos lugares (LEITE, 2008, p. 181).

Pressupõe-se, nesses espaços, uma heterogeneidade étnica e cultural, que funciona como ferramenta para remeter a espaços de tolerância e de prosperidade. Sánchez problematiza essa noção, afirmando que essas imagens são apropriadas enquanto recurso mercadológico, estetizando as relações sociais e simplificando o diverso para mascarar os conflitos que este suscita. Essa pasteurização da cultura faz parte de uma estratégia de renovação urbana, que promove uma "ordem branca da cultura" (SÁNCHEZ, 2011, p. 505). Isso significa dizer que, na cidade, o ambiente pacífico é uma prioridade porque suscita um clima favorável aos negócios,

\footnotetext{
${ }^{3}$ Abreviados, respectivamente, de South of Houston Street e Triangle Below Canal Street, os bairros de SoHo e TriBeCa são antigas áreas industriais têxteis de Manhattan, consideradas indesejáveis para habitar durante a primeira metade do século $X X$, quando a atividade fabril se descentralizou para outros distritos metropolitanos. A partir da década de 1960, com o surgimento de grupos de artistas interessados na arquitetura local e nos baixos valores de troca do solo, iniciou-se um processo de revalorização da área, que integra, desde 1973, o Comitê de Preservação de Marcos de Nova lorque.
} 
sem que isso represente necessariamente o exercício da cidadania.

A "cidade-empresa-cultural" (ARANTES, 2013, p. 34) produz uma simbiose entre imagem e produto, projetando a cidade como um ambiente homogêneo e livre dos conflitos sociais. $\mathrm{O}^{\circ}{ }^{\circ}$ distrito se insere em uma dinâmica de preservação de formas e substituição de funções do patrimônio cultural urbano-industrial em todo o mundo, onde se transfere a simbologia da prosperidade industrial para a promessa de uma prosperidade tecnológica e criativa do terceiro setor da economia. A preservação perde seu caráter histórico para a esfera do consumo, sendo não recuperada, mas recriada, como uma re-representação/dramatização dos costumes, acrítica, com vistas à viabilização econômica como dimensão preponderante. Preservação, nesses moldes, é entendida como revalorização econômica.

O surgimento de um regramento específico, na figura do Masterplan, como são hoje as iniciativas de planejamento estratégico, chama a atenção por se fazer a par das prerrogativas do Plano Diretor de Desenvolvimento Urbano Ambiental (PDDUA) de Porto Alegre, promovendo desapropriações e densificações ${ }^{4}$. Como este instrumento ainda se encontra em fase inicial de implementação, não é possível analisar suas reverberações na área de estudo. Contudo, se identifica a predominância da dimensão estética que vem se atribuindo ao patrimônio cultural urbano, cujo papel é, sobretudo, de elemento de distinção dentro da cidade. $\mathrm{Na}$ era do planejamento estratégico, dissipa-se o compromisso efetivo de resgate da memória coletiva. A partir de um conjunto que compreende o material e o imaterial, as normativas e os discursos, a valorização econômica da área reverbera a agenda global de requalificação das áreas industriais, tão suscetíveis à especulação imobiliária.

\section{Considerações finais}

A recente valorização do patrimônio cultural urbano, negligenciado por décadas, influencia o valor de troca das áreas do entorno, ou seja, do 4ํㅡㄹ Distrito como um todo, colocando a preservação como uma potente ferramenta na reprodução do espaço urbano. Uma área digna de preservar possui, portanto, uma virtude, que reverbera economicamente. Pensar a preservação como promotora de qualidade de vida traz consigo uma noção de sustentabilidade, que respeita o passado enquanto prepara o lugar para o desenvolvimento futuro. Logo, se pensarmos o patrimônio como recurso, este se enquadra na categoria não-renovável. A festa de Nossa Senhora dos Navegantes, no dia 2 de Fevereiro, patrimônio imaterial de Porto Alegre, é um exemplo da singularidade que a memória resguarda, não podendo ser replicada. Nesse sentido, o patrimônio torna-se um elemento estabilizador da memória coletiva a partir do resgate das afetividades.

A preservação é uma estratégia, balizada pelo princípio da sustentabilidade, que busca, em última instância, o desenvolvimento. Este deve contemplar as diferentes realidades e demandas dos sujeitos que vivenciam o espaço, para que o patrimônio não seja apropriado enquanto um elemento de distinção - e, consequentemente, de exclusão. A ideia de um patrimônio perpassa a noção de operarcomo um agregador, um incorporador; que deve refletir a(s) memória(s) de uma coletividade. A transformação do $4^{\circ}$ Distrito, portanto, requer um olhar cauteloso, que suscite quais as diferentes concepções que orbitam o local, e quais são as percepções e reivindicações da população que anima aquele espaço. Ultimamente, essa população estabelece relações de duas ordens: relações de base concreta, ou seja, de uso, necessidade e oportunidade; e relações de base simbólica, onde imperam cognições subjetivas, como pertença, memória e legado.

Por isso, é importante pensar o par preservação-desenvolvimento no 4ํㅡㄹ Distrito: os caminhos

\footnotetext{
${ }^{4}$ Regramento de exceção, Masterplan aparece nas mídias locais como instrumento de revalorização econômica do $4^{\circ}$ Distrito: <http://zh.clicrbs.com.br/rs/porto-alegre/noticia/2016/12/revitalizacao-do-4-distrito-preve-desapropriacoes-emcinco-bairros-8843370.html>
} 
escolhidos pelo poder público, enquanto mediador do processo, serão determinantes para o uso que se fará da região, e por quais grupos sociais. A lisura dos mecanismos de regulação, na figura do planejamento, é que garante a segurança de que a identidade cultural da região seja preservada, para além de suas formas urbanas; uma integridade que faz menção, antes de tudo, aos seus habitantes, que carregam sua memória. A participação desses atores nos espaços decisórios é essencial para que as mudanças em curso sejam referendadas e revestidas de uma legitimidade própria da cidadania. Em um espaço tão singular de Porto Alegre, a preservação da ambiência urbana aliada ao desenvolvimento se mostra um tema significativo, bem como abre um amplo escopo de investigação para todas as ciências que se ocupam, em diferentes abordagens, do espaço urbano, em toda a sua complexidade.

\section{Referências}

ARANTES, O. B. F. Uma estratégia fatal: a cultura nas novas gestões urbanas. In: ARANTES, O. B. F., VAINER, C. B., MARICATO, E. A cidade do pensamento único - desmanchando consensos. Petrópolis, RJ: Editora Vozes, 2013.

CONTASSOT, P. T. P. Transformações no padrão de habitação do 4 Distrito de Porto Alegre. Monografia (Bacharelado em Geografia) - Instituto de Geociências, Universidade Federal do Rio Grande do Sul, Porto Alegre. 2014. 101 p. Disponível em: <https://www.lume.ufrgs.br/bitstream/handle/10183/114634/000955442.pdf?sequence=1>

CASTELLO, L. Há lugar para o lugar na cidade do século XXI? Revista virtual Arqtexto. № 5. Porto Alegre, 2004.

LEFEBVRE, H. O direito à cidade. São Paulo: Centauro, 2001.

LEFEBVRE, H. A revolução urbana. Belo Horizonte: Editora UFMG, 1999.

LEITE, R. P. (Org.). Cultura e vida urbana: ensaios sobre a cidade. São Cristóvão: Editora UFS, 2008.

LIPOVETSKY, G.; SERROY, J. A estetização do mundo - viver na era do capitalismo artista. 1르. Ed. São Paulo: Companhia das letras, 2015.

MEIRA, A. L. O passado no futuro da cidade: políticas públicas e participação popular na preservação do patrimônio cultural de Porto Alegre. Porto Alegre: Editora UFRGS, 2004.

MONTEIRO, M. Revitalização do $4^{\circ}$ Distrito prevê desapropriações em cinco bairros. Jornal Zero Hora, Porto Alegre, 21 de Dez. de 2016. Disponível em: <http://zh.clicrbs.com.br/rs/portoalegre/noticia/2016/12/revitalizacao-do-4-distrito-preve-desapropriacoes-em-cinco-bairros-

8843370.html> Acesso em: Maio de 2016.

SÁNCHEZ, F. A reinvenção das cidades para um mercado mundial. 2. ed. Chapecó, SC: Argos, 2010.

SANTOS, M. A natureza do espaço. São Paulo: EdUSP, 2006.

PORTO ALEGRE. Plano Diretor de Desenvolvimento Urbano Ambiental. Porto Alegre, 2010.

PORTO ALEGRE. Secretaria Municipal de Urbanismo. UFRGS apresenta estudo de revitalização do $4^{\circ}$ Distrito. Disponível em: <http://www2.portoalegre.rs.gov.br/spm/default.php?p_noticia=190964\&UFRGS+APRESENTA+ ESTUDO+DE+REVITALIZACAO+DO+4O+DISTRITO\%3E> Acesso em: 15 de Maio de 2017.

VIVANT, E. O que é uma cidade criativa? São Paulo: Editora Senac, 2012. 